Results We revealed nucleotide missens VUS: c.1259A>G, p. Q420R and c.2051T >C, p.I684T in the heterozygous state in LZTR1 gene. All variants were absent in HGMD professional and gemome aggregatioonal database.

Conclusion Child with severe hypertrophic cardiomyopathy and typical phenotype of Noonan syndrome was detected NS 2 , caused by compound heterozygous missense variants c.2051T>C, p.I684T and c.1259A>G, p.Q420R in LZTR1 gene.

\section{ECHOCARDIOGRAPHIC FINDINGS IN TUBEROUS SCLEROSIS COMPLEX-SINGLE INSTITUTION EXPERIENCE}

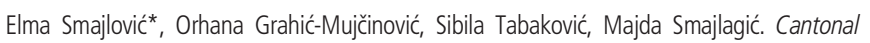
Hospital Zenica, $\mathrm{BH}$

\subsection{6/archdischild-2021-europaediatrics.176}

Tuberous sclerosis complex (TSC) is a relatively rare autosomal dominant disorder characterized by hamartomatous lesions in a variety of organs.

Cardiac involvement remains within major criteria for diagnosing the syndrom, as it can initiate the TSC evaluation for some patients. Cardiac involvement is usually maximal at birth or early infancy and shows signs of regression during the first two years of life. The aim of this study was to evaluate the echocardiographic findings in our patients with tuberous sclerosis complex.

We present a case series of five patients diagnosed with TSC in our hospital within the last ten years. All patients underwent a complete cardiac examination at the time of diagnosis (clinical findings, electrocardiography and ultrasound examination of the heart) and were further monitored through controls.

All patients had a normal clinical findings. One patient had nonsignificant supraventricular and ventricular extrasystoles. Abnormal echocardiographic findings were seen in four of total five patients. Two patients had both atrial and ventricular cardiac masses with echo characteristics that raised suspicion of rhabdomyoma. Two other patients had multiple focal areas of increased intramyocardial echogenicity. There were no signs of outflow tract obstruction or impaired valvular function. Left ventricular size and function were normal. Close follow up showed no signs of significant regression or progression in our echocardiographic findings.

The prognosis and growth potential of these masses are not known, but can be determined by longitudinal follow-up. Cardiac ultrasound should be considered for all patients with TSC regardless of physical findings.

\section{RARE CASE OF UHL'S ANOMALY IN AN ADOLESCENT}

Matija Bakoš ${ }^{\star}$ Daniel Dilber, Marina Mihalec, Dorotea Bartoniček, Ivan Malčić, Darko Anić, Dražen Belina, Dalibor Šarić. University Hospital Center Zagreb

\subsection{6/archdischild-2021-europaediatrics. 177}

Uhl's anomaly is an extremely rare congenital heart defect of an unknown cause, characterized by the absence of the myocardium in the right ventricular free wall, which is replaced by nonfunctional fibroblastic tissue.
We present a case of 14 year old boy after heart transplantation and care due to Uhl's anomaly diagnosed five years ago. Five years before this admission, child experienced exertional dyspnea and vertigo at school.

During transport to the hospital, child arrested and after a short resuscitation and defibrillation (initial rhythm VF), sinus rhythm occurred.

On the initial transthoracic echocardiography, dilated cardiomyopathy of right ventricle was observed. After the initial stabilization, MR was performed (May 2014.), where marked dilatation and impaired function of both right atrium and ventricle was noticed. The volume of right ventricle in diastole (EDV) was $245 \mathrm{ml}(188 \mathrm{ml} / \mathrm{m} 2)$ with ejection fraction of RV of $19 \%$.

The RV wall was thin, with almost complete absence of right ventricular free wall myocardium, without fat infiltration. Control MR, performed after one year, showed a progression in dilatation of right ventricle dimensions with impressive tricuspid regurgitation. The left heart structures, functionally, and morphologically, were within normal range. Differential diagnosis yielded two possiblites: Uhl's anomaly and aritmogenic dysplasia of right ventricle (ARVD).The recommended biopsy, as well as installation of implantable cardioverter defibrillator, were rejected by his parents. The metabolic diseases were excluded. From June 2018, child was dyspneic in everyday activities, had peripheral edema, was tired and sometimes complaining off tingling in the legs. After two rejections from his parents, heart transplantation was done in January 2019. Pathohistological diagnosis of Uhl's anomaly was confirmed. One month later, he was discharged from the hospital.

It is a question of differentiation between Uhl's anomaly and ARVD. In ARVD, the myocardium is progressively replaced by fibrofatty tissue, and has been linked to mutations in the genes encoding plakoglobin and desmoplakin.

Patients with Uhl's anomaly rarely survive to adulthood. There are two main surgical approaches for these patients; first one is based on the relief of right ventricle volume or excluding the entire right heart from circulation. This can be done by making total cavopulmonary connection, by closing tricuspid valve and making bidirectional Glenn procedure, or making a one-and-a-half ventricle repair with plication of the right ventricular free wall. Second option is the heart transplantation.

\section{PERIOPERATIVE MYOCARDIAL PERFORMANCE IN INFANTS WITH DOWN SYNDROME UNDERGOING CONGENITAL HEART DISEASE REPAIR: A COMPARISON WITH INFANTS WITH A NORMAL CHROMOSOME COMPLEMENT}

Lyudmyla Zakharchenko*, Eleanor Molloy, Colm Breatnach, Afif EL-Khuffash, Orla Franklin. RCSI, Children's Health Ireland, Crumlin Hospital

\subsection{6/archdischild-2021-europaediatrics. 178}

Infants with Down Syndrome (DS) undergoing surgical correction of congenital heart disease (CHD) may exhibit altered loading conditions and myocardial performance during the peri-operative period when compared with counterparts with a normal chromosome complement. This my result in higher morbidity. We aimed to characterise the impact of DS on myocardial performance and loading conditions in infants with 
CHD over the perioperative period by comparing them with genetically normal controls, matched for cardiac lesion.

Infants with DS and with CHD of atrioventricular septal defect (AVSD) and ventricular septal defect (VSD) were prospectively recruited to undergo three echocardiograms (preoperatively, post-operatively within 24 hours and pre-discharge from hospital). Left (LV) and right (RV) ventricular function was measured using deformation analysis to derive LV global longitudinal strain (LV GLS) and RV free wall longitudinal strain (RV FwLS). LV end systolic wall stress (ESWS) and RV systolic pressure (RVSp) were also measured. A non-DS control group with VSD and AVSD were recruited for comparison. Data on cardiorespiratory parameters, complications, and length of stay were compared.

34 infants with DS were compared with 17 controls. LVGLS was significantly higher in the DS group at echo 1 and 3. LVGLS decreased in both groups post-operatively with neither group recovering to preoperative values pre-discharge. RV FwLS significantly decreased in both groups post-operatively with controls demonstrating better recovery by hospital discharge. ESWS was lower and RVSp was higher in the DS group throughout the study period. Post-operatively, infants with DS had higher vasoactive inotropic scores, longer duration of inotropic support and total duration of PICU stay. Chylothorax was seen exclusively in the DS population.

Infants with DS and CHD demonstrate increased LVGLS and lower ESWS peri-operatively. There was a lower recovery in RV function observed pre-discharge in DS infants with a higher RVSp. They also exhibit an increase disease burden post-operatively. This may reflect the autonomic dysfunction described in infants with DS who have lower systemic but higher pulmonary vascular resistance, although this requires further evaluation.

\section{EVALUATION OF THE OF LIPID PEROXIDATION REACTIONS AND REGIONAL BLOOD FLOW OF PERIODONTAL TISSUES IN ADOLESCENTS WITH ARTERIAL HYPERTENSION AND PERIODONTAL DISEASES}

Marina Darenskaya, Lyubov Rychkova*, Larisa Kolesnikova, Anna Pogodina, Lyudmila Grebenkina, Sergei Kolesnikov, Lyubov Kolesnikova. Scientific Centre for Family Health and Human Reproduction Problems, Irkutsk, the Russian Federation

\subsection{6/archdischild-2021-europaediatrics. 179}

To study lipid peroxidation and periodontal tissues regional blood flow parameters in adolescents with arterial hypertension and periodontal diseases 94 adolescents group with arterial hypertension $(\mathrm{AH})$ and periodontal disease $(\mathrm{n}=57$, mean age of $14.7 \pm 1.89$ years) and a group without $\mathrm{AH}$ and with periodontal disease $(n=37$, mean age of $14.57 \pm 2.01$ years $)$ (comparison group) were examined. The intensity of lipid peroxidation (LPO) processes was assessed by spectrophotometric and fluorometric methods. The method of Doppler ultrasound was used for the assessment of periodontium hemodynamic and microvascularization.

The group of adolescents with $\mathrm{AH}$ and periodontal diseases characterized by the statistically significant differences with the comparison group in primary products of LPO - diene conjugates (1.53 times lower, $\mathrm{p}=0.0002)$, thiobarbituric acid reactive products (TBA-active products) increase (by 1.4 times, $\mathrm{p}=0.0018$ ), decrease of of $\alpha$-tocopherol level (by 1.3 times, $\mathrm{p}=0.0013$ ) and retinol level increase (by 1.25 times, $\mathrm{p}=0.014)$. The group with $\mathrm{AH}$ and with periodontal disease had an increased values of the blood flow velocity in the systole (1.12 time, $\mathrm{p}=0.010)$ and index of peripheral resistance (1.19 times, $\mathrm{p}<0.0001)$ compared with the data of the comparison group. In the group of adolescents with $\mathrm{AH}$ with periodontal disease the appearance of pathological dependencies between toxic metabolites of the lipid peroxidation process and indices of vascular blood flow was noted.

Imbalance in the LPO-AOD system as well as the appearance of pathological relationships between the parameters of lipid peroxidation and the parameters characterizing reduction of vascular blood flow in adolescents with hypertension and periodontal disease was proved and it can be the new comorbid association.

\section{THE ASSOCIATION OF PRENATALLY DIAGNOSED CARDIAC RHABDOMYOMA AND TUBEROUS SCLEROSIS COMPLEX}

Ana Ćrić* ${ }^{*}$ Tomislav Ćaleta, Iva Vukšić, Petra Džepina, Dorotea Ninković, Andrea Dasović Buljević, Vesna Benjak, Boris Filipović-Grčić, Dalibor Šarić, Daniel Dilber, Nada Sindičić Dessardo, Ruža Grizelj. Department of Pediatrics, University Hospital Centre Zagreb, University of Zagreb, School of Medicine

\subsection{6/archdischild-2021-europaediatrics. 180}

Although rare, cardiac rhabdomyomas (CRs) are the most common fetal cardiac tumors. They may be the earliest manifestation of tuberous sclerosis complex (TSC). TSC is diagnosed in $75-80 \%$ cases of multiple fetal CRs and in $30 \%$ of single cases. We retrospectively reviewed the clinical outcome of fetal CR cases.

All cases of prenatally diagnosed rhabdomyoma in a single tertiary centre from 2009 to 2019 were ascertained from medical records.

We identified 14 fetuses with prenatally diagnosed CRs. Mean period of follow-up was 4 years (range $4 \mathrm{~m}-9 \mathrm{y}$ ). Two fetuses were twins (BC/BA), both affected by CR with family history of TSC, and one fetus of the dichorionic pair was not affected by rhabdomyoma. The mean GA at diagnosis was 29 weeks (range 21-35). There were eleven fetuses with multiple, and three with a solitary tumor. The right and left ventricle as well as the intraventricular septum were equally affected with a slight predominance of the left ventricle. The cardiac atrium was affected in two cases. The size ranged from small tumors of several $\mathrm{mm}$ in diameter up to dimensions of $20 \times 20$ mm.

Sixty percent were $<20 \mathrm{~mm}$ in diameter. Two of fetuses were affected by hemodynamically relevant cardiac obstruction (LVOT), and in four arrhythmias (SVES, VES, WPW syndrome, and AV block) were observed. No hydrops fetalis or fetal perinatal demise were observed. In 11 (79\%) TSC was confirmed clinically or by mutational analysis. After birth, most rhabdomyomas demonstrated a stable $(14 \%, n=2)$ or spontaneous regressive growth pattern $(57 \%, n=8)$. In four children (29\%) tumors entirely disappeared. No progression of tumor size or number was observed. After birth in five (36\%) children the conduction abnormalities were confirmed by ECG and responded well to the anti-arrhythmic medication and two children were affected by LVOT obstruction. Cerebral manifestations (tubers and/or nodules) were detected by brain MRI in 9 patients ( 3 prenatally). Subependymal giant cell 